Brit. J. soc. Med. (1949), 4, 220-227.

\title{
MORTALITY FROM TUBERCULOSIS IN SOME COUNTRIES
}

\author{
BY
}

\author{
GUNNAR DAHLBERG
}

From the State Institute for Human Genetics and Race Biology, University of Uppsala

Comparison of THE Tuberculosis Death-Rate in VARIOUS COUNTRIES

Valid comparison between tuberculosis mortality rates of different countries has to take stock of the fact that the death-rate from tuberculosis is not the same for the two sexes and of the fact that it is not the same in different age groups. It is, therefore, misleading to compare crude rates, i.e. the annual number of deaths per 1,000 inhabitants. Obviously, a country, with a high birth-rate will have a high death-rate from tuberculosis if the tuberculosis death-rate is very high among very young persons (less than 1 year old), albeit the death-rates for separate age groups might not then show any differences at all. To eliminate the source of error inherent in this circumstance, one may use figures for the cumulative risk of dying from tuberculosis, by adding figures for the various age groups. Figures obtained by this means are independent of the age distribution of the population. We may thus follow up 1,000 persons through the course of life and calculate how many die from tuberculosis provided that they do not die for some other reason.

TABLE I

Tuberculosis Death-Rate in Different Age groups In ENGlaNd, France, AND SWEDEN

\begin{tabular}{|c|c|c|c|c|c|c|}
\hline \multirow{2}{*}{ Age (years) } & \multicolumn{2}{|c|}{$\begin{array}{l}\text { England and } \\
\text { Wales, } 1936\end{array}$} & \multicolumn{2}{|c|}{$\begin{array}{l}\text { France, } \\
1931-35\end{array}$} & \multicolumn{2}{|c|}{$\begin{array}{l}\text { Sweden, } \\
1931-35\end{array}$} \\
\hline & M. & F. & M. & F. & M. & F. \\
\hline $\begin{array}{r}5 \\
10 \\
15 \\
20 \\
25 \\
30 \\
35 \\
40 \\
45 \\
50\end{array}$ & $\begin{array}{r}0.4 \\
0.5 \\
0.7 \\
2.5 \\
6.5 \\
10.8 \\
14.9 \\
19.6 \\
24.5 \\
30.5\end{array}$ & $\begin{array}{r}0 \cdot 4 \\
0 \cdot 5 \\
1 \cdot 1 \\
4 \cdot 4 \\
9 \cdot 8 \\
14 \cdot 1 \\
17 \cdot 4 \\
20 \cdot 3 \\
22 \cdot 7 \\
24 \cdot 8\end{array}$ & $\begin{array}{r}0.9 \\
1.3 \\
2.0 \\
5.6 \\
13 \cdot 1 \\
21 \cdot 8 \\
32 \cdot 5 \\
44 \cdot 2 \\
55 \cdot 9 \\
68 \cdot 0\end{array}$ & $\begin{array}{r}0.9 \\
1.3 \\
2.7 \\
8 \cdot 5 \\
17 \cdot 5 \\
25 \cdot 9 \\
32 \cdot 9 \\
39 \cdot 0 \\
44 \cdot 3 \\
48 \cdot 8\end{array}$ & $\begin{array}{r}0 \cdot 7 \\
1 \cdot 1 \\
1 \cdot 8 \\
5.9 \\
13 \cdot 2 \\
20 \cdot 2 \\
26 \cdot 1 \\
31 \cdot 4 \\
36 \cdot 2 \\
40 \cdot 8\end{array}$ & $\begin{array}{r}0.7 \\
1.2 \\
2.6 \\
8.6 \\
17.7 \\
25.9 \\
32.6 \\
38.0 \\
42.6 \\
46.5\end{array}$ \\
\hline
\end{tabular}

In doing so, one neglects differences with referenced to general mortality in different populations; but if it is desirable to take this into account we can express

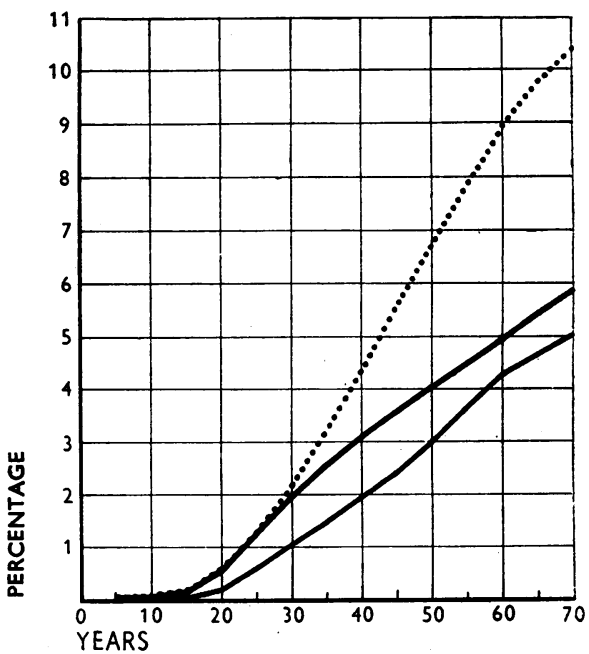

FIG. 1.-Diagram of the cumulative death-rate from tuberculosis up to different age-limits for men, in France? (the dotted line), Sweden (the upper whole line), and England (the lower whole line).

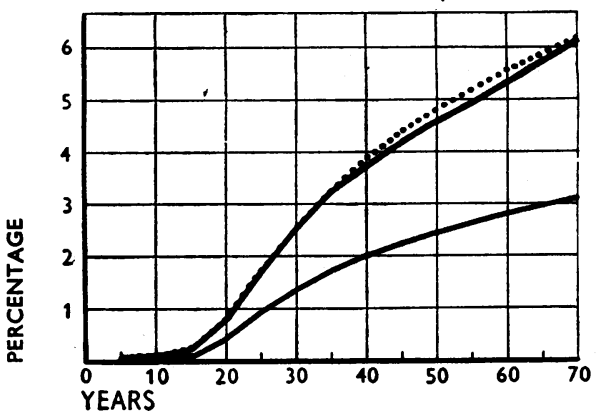

FIG. 2.-Diagram of the cumulative death-rate' from? tuberculosis up to different age-limits for women, in France (the dotted line), Sweden (the upper whole line), and England (the lower whole line). 
TABLE II

Comparison between the Tuberculosis Death-rates in Different Countries

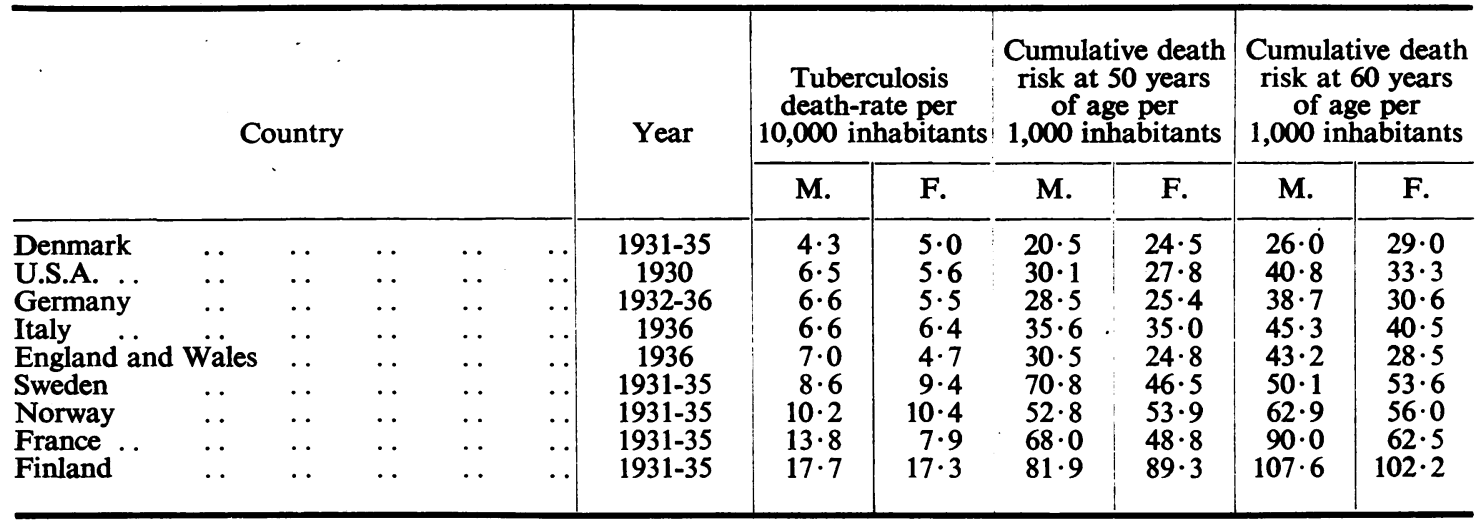

the tuberculosis death-rate as a percentage of the general death-rate. The percentage will, of course, be different in different age groups. In comparing different populations, it may then be useful to cite the mean of percentage for all age groups.

Table I and Figs. 1 and 2 cite cumulative or total death risk for England and Wales (1936), France (1931-35), and Sweden (1934-36) to illustrate how to carry out the relevant computations. At the age limit of 50 years we find that $4 \cdot 1$ out of 100 Swedish men die of pulmonary tuberculosis, and 4.6 out of 100 women. Corresponding figures for England are $3 \cdot 1$ and $2 \cdot 5$. The figures for France are higher, 6.8 for men and 4.9 for women.

Table II cites for different countries both the cumulative death-rate from pulmonary tuberculosis up to 50 years, and the ordinary death-rate, i.e. how

TABLE III

Comparison between the Percentual Tuberculosis DeATH-RATES In Different COUNTRIES

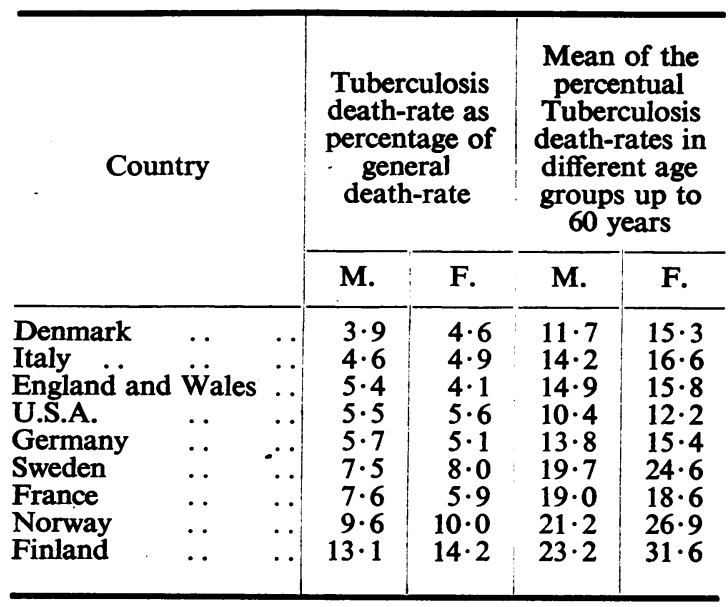

many die per 10,000 persons. It exhibits both the differences with regard to risk of death at two age levels, and also what distortion of the risk may arise from reliance on crude death-rates. Table III exhibits the overall death-rate in tuberculosis expressed as a percentage of the general death-rate. It also cites mean figures of the percentage of deaths from pulmonary tuberculosis out of all deaths in various age groups.

Relevant comment on the contents of these tables will be found below. Here it suffices to emphasize the value of figures for cumulative risk if our aim is to compare statistics of different countries.

\section{The Number of Tuberculin-positive Persons in SWEDEN}

By making tuberculin tests it may fairly certainly be ascertained whether a person has ever been infected by tuberculosis. Different kinds of tuberculin tests exist, but nowadays it is generally held that the Mantoux test, involving an intracutaneous injection of $1 \mathrm{mg}$. tuberculin, gives the best results. In Sweden, Mantoux tuberculin tests have now been carried out on a comparatively large scale thanks to the National Anti-Tuberculosis League. It has thus been possible to get some idea of the number of persons infected by tuberculosis in the Swedish population. The material comprised 11,500 individuals, and a statistical treatment of the data was carried out in the State Institute for Human Genetics and Race Biology. Fig. 3 (overleaf) shows that the incidence of tuberculin-positive reaction rapidly increases from school age onwards, and attains a maximum in the age group 40-45, by which time 98 per cent. of the population is Mantoux-positive. It may further be stated that the frequency of tuberculin-positive reaction seems to drop slightly in the higher age 
groups, i.e. after 60 years of age. Moreover, it is interesting to note that the curve for women seems to lie consistently at a slightly lower level than that for men. The difference is not large but it is statistically significant throughout, and is greatest about the age of 25 .

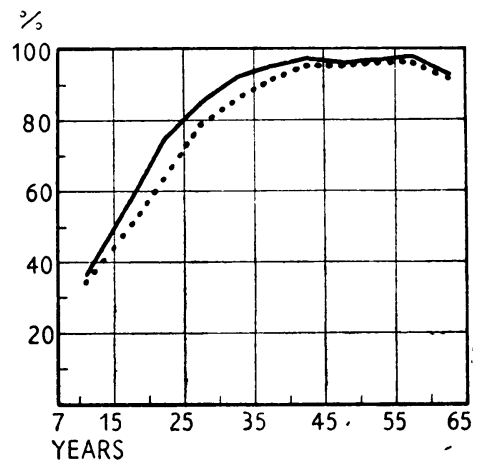

FIG. 3.-Percentage of tuberculin-positive persons in different age-groups in Sweden.

Dotted line $=$ women. $\quad$ Whole line $=$ men .

In any case, the figures obtained show that: (a) almost every individual sooner or later becomes tuberculin-positive; $(b)$ under the social conditions existent in Sweden this occurs in many instances well on in adult life. Seemingly, no comparable figures are available for other countries. If tuberculin surveys have been carried out elsewhere, the numerical material does not seem to have been assembled in this form; but we may assume that data from other countries, if available, would follow a similar curve.

\section{The Specific Death-Rate from Tuberculosis at Various Ages in Different Countries}

Fig. 4 shows the age distribution of the tuberculosis death-rate in Sweden. It is high during the first year of life, sinks to a minimum about the age of 5 and again increases to a maximum in the 25-year-olds. It then drops anew to rise again, but not so much, about the age of 60 . It is remarkable, furthermore, that: (a) the tuberculosis deathrate apparently increases, first in women and somewhat later in men, up to the age of $25 ;(b)$ men have a higher mortality than women about the age of 50, though the difference is not large. It should be emphasized that curves referable to different decades are comparable, though the general level is higher at an earlier period.

Fig. 5 discloses the picture for Norway in the years 1931-35. The contour of the curves is much the

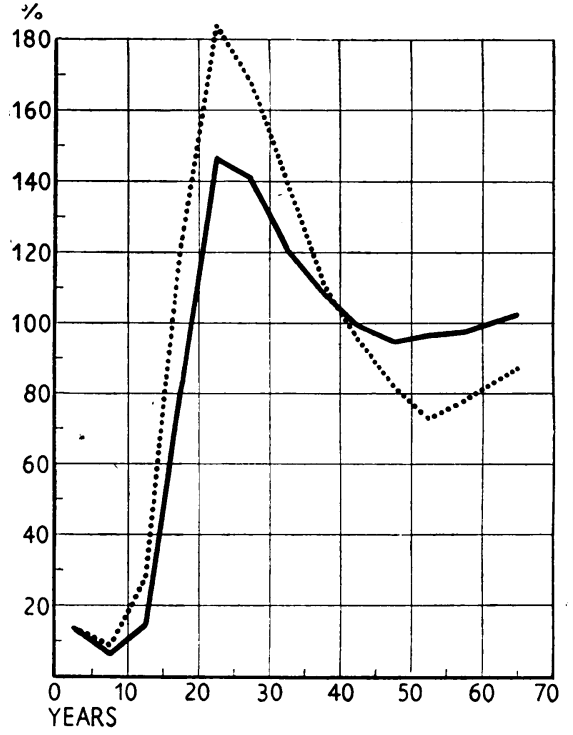

FIG. 4.-Tuberculosis death-rates in Sweden, 1931-35. Dotted line $=$ women. Whole line $=$ men.

same as in Fig. 4, but the sex difference in Norwarg $\frac{\overrightarrow{0}}{0}$ is more striking. Men show a higher mortality rate but the tuberculosis death-rate of women still rise

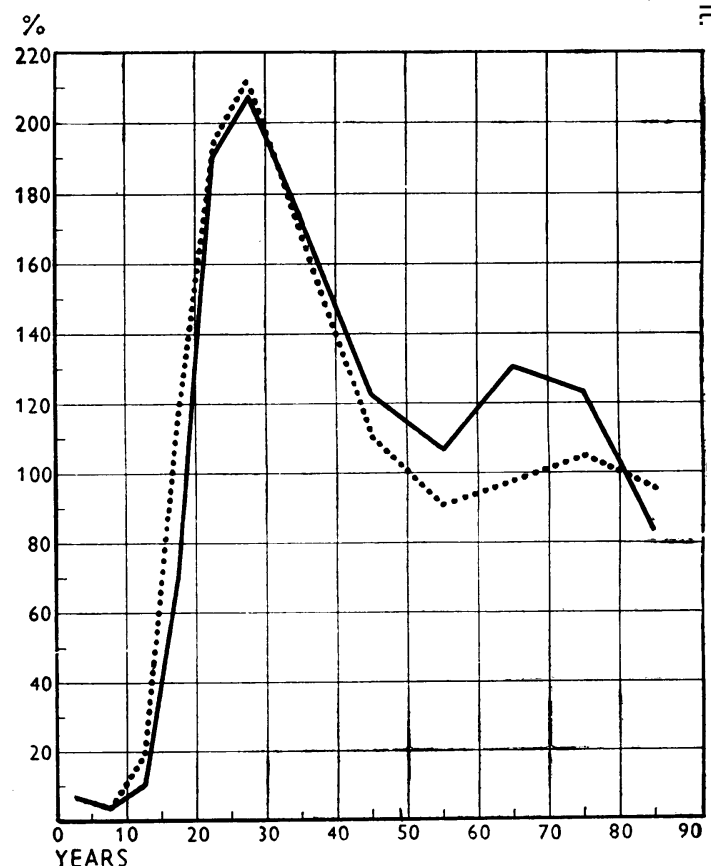

FIG. 5.-Tuberculosis death-rates in Norway, 1931-35. Dotted line $=$ women. $\quad$ Whole line $=$ men. 
$\%$

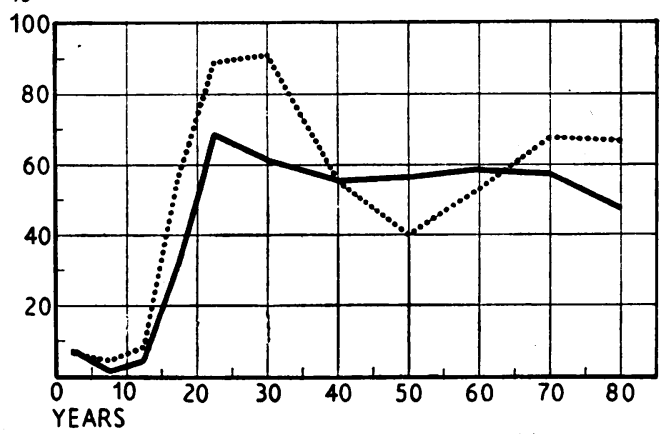

FIG. 6. - Tuberculosis death-rates in Denmark, 1931-35. Dotted line $=$ women. Whole line $=$ men.

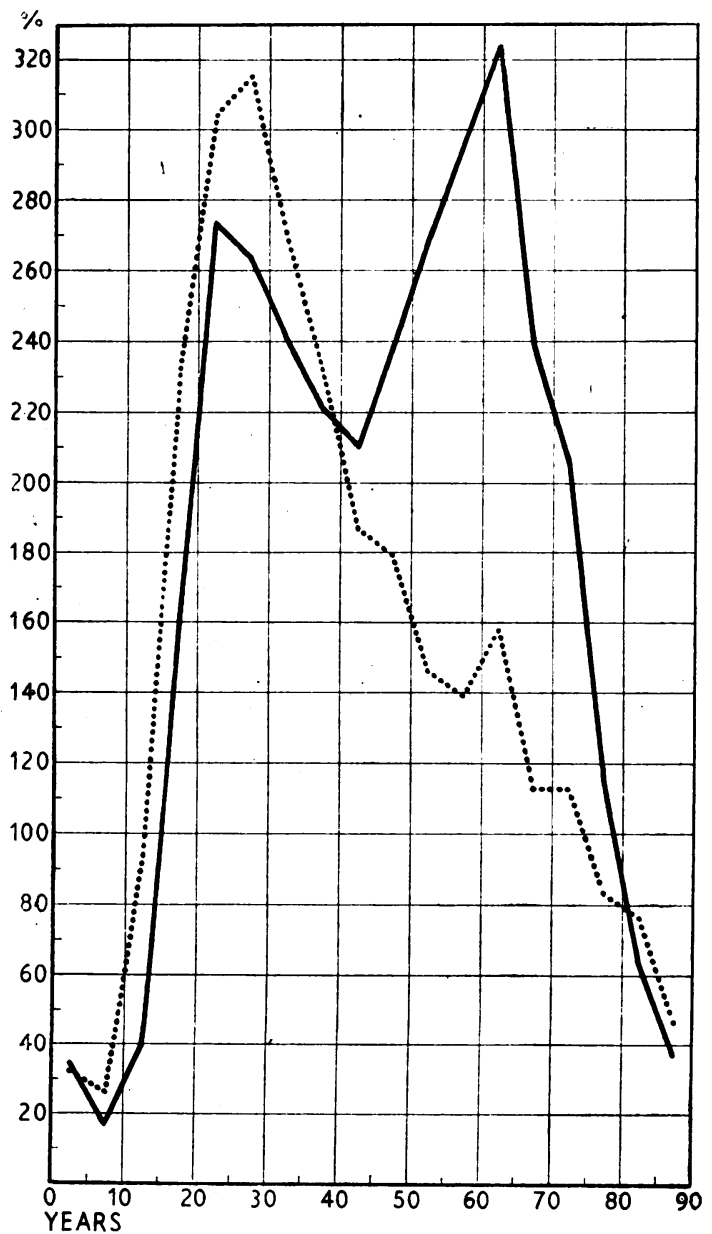

Fig. 7.-Tuberculosis death-rates in Finland, 1931-35. Dotted line $=$ women. Whole line $=$ men. somewhat earlier. Corresponding statistics for Denmark (Fig. 6) differ as a whole more conspicuously from those of Sweden. The mortality amongst women reaches its maximum about the age of 30 , falling thereafter, while that amongst men continues to rise to an advanced age.

Finland takes an intermediate position (Fig. 7). The death-rate for women has the same hump as in the countries already discussed. The men, on the other hand, reach a maximum about the age of 25 , whereupon their mortality decreases, to rise again as from the age of 40 . Apart from this, the tuberculosis mortality in Finland lies on a far higher level than in the other Nordic countries.

It would be merely tiresome to include tuberculosis mortality data for all the countries for which statistics are available. We therefore confine ourselves to those of England and Wales, Germany,

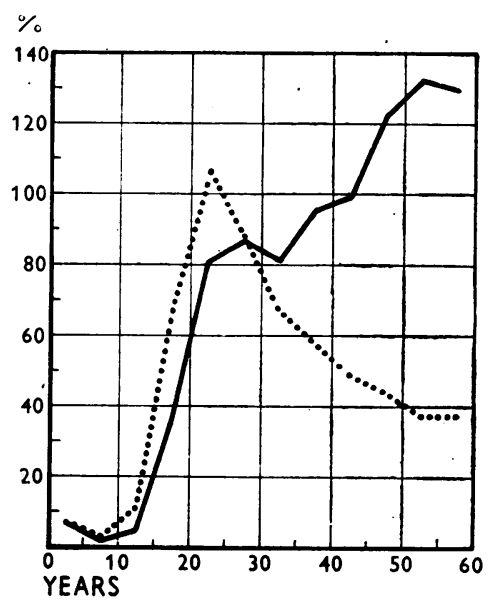

Fig. 8. - Tuberculosis death-rates in England and Wales, 1936. Dotted line $=$ women. Whole line $=$ men.

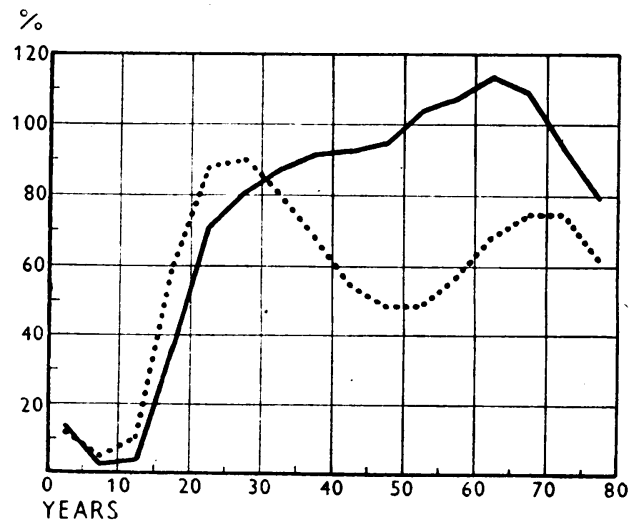

FIG. 9. -Tuberculosis death-rates in Germany, 1932-36. Dotted line $=$ women. Whole line $=$ men. 


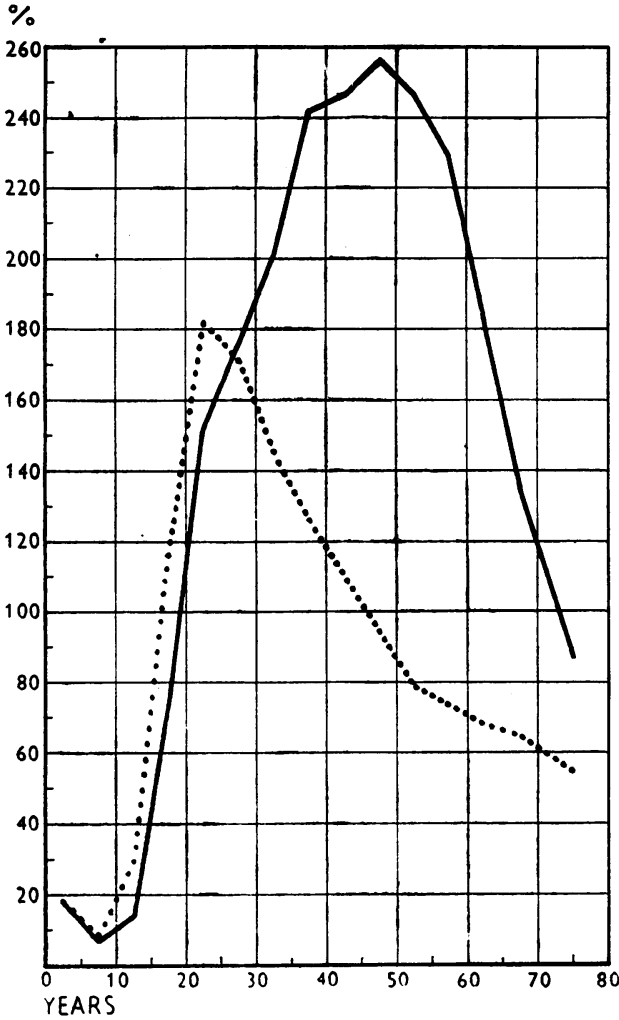

FIG. 10.-Tuberculosis death-rates in France, 1931-36. Dotted line $=$ women. $\quad$ Whole line $=$ men.

France, Italy, and the U.S.A. It should be emphasized that the curves in Figs 8-12 are drawn to the same scale, and are consequently comparable. They all refer to the years before the second world war. It is remarkable that they lie on such different high levels. Common to all is the fact that mortality of women drops after the age of 30 while in men it continues to rise. In this respect, the difference between the sexes is most pronounced in France, and that country also exhibits the peculiarity that in old age male mortality has a downward trend.

\section{Discussion}

Common to all the data cited, as repeatedly emphasized, is the more rapid rise of the death-rate from tuberculosis before the age of 20 in women as compared with men. One gains the impression that puberty plays a decisive part in this phenomenon. For as a rule puberty sets in earlier in females than in males. Whether or not hormonal readjustment taking place at this time makes any difference, or whether the causative factor underlying the increase

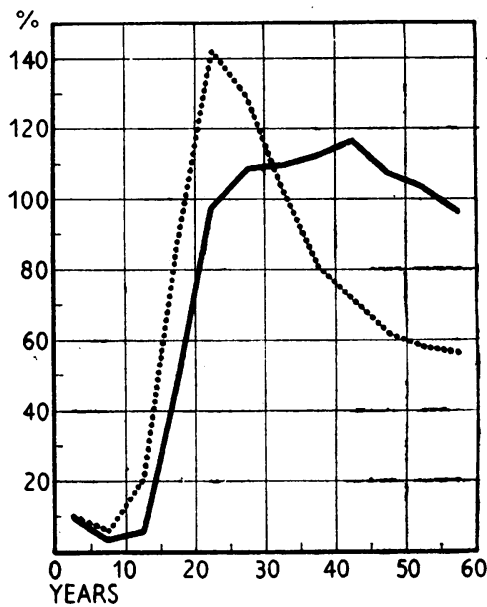

Fig. 11.-Tuberculosis death-rates in Italy, 1936. Dotted line $=$ women. $\quad$ Whole line $=$ men

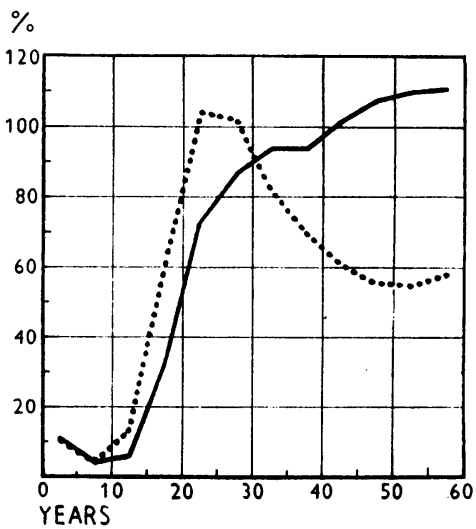

FIG. 12.-Tuberculosis death-rates in the U.S.A., 1930 Dotted line $=$ women. Whole line $=$ men.

is the beginning of work, it is at present impossibie to decide.

A second issue worthy of comment is the differenge between trends for men and women after the age of 30. In two Scandinavian countries the cure drops in the same way for both men and wome though the male decrease is less pronounced. PR Denmark, on the other hand, the curve rises aft the age of 30 for men but not for women, and the same thing happens in the larger countries. Natug:ally these discrepancies cannot be due to unreliable figures. Differences of the magnitude we afe dealing with here can hardly have such causef. Nor can it be assumed that racial differences are to blame. For a racial difference could scarcely affeet the men only. 


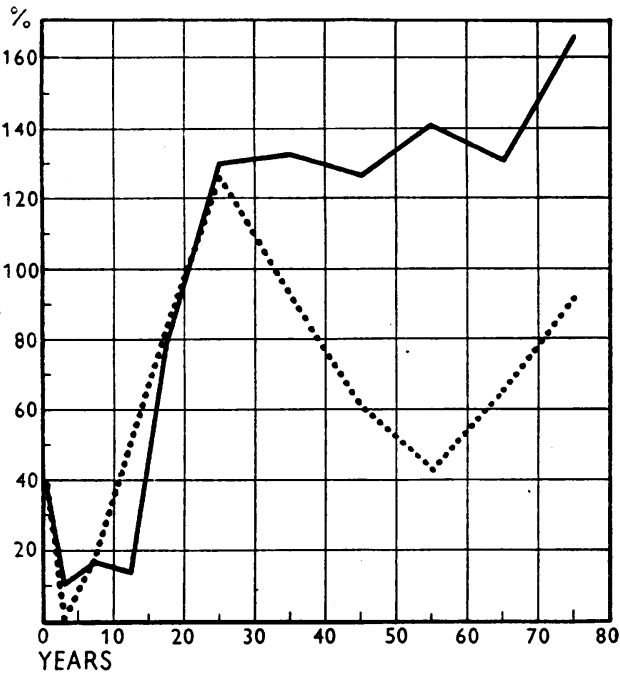

FIG. 13.-Tuberculosis death-rates in Stockholm, 1934-36. Dotted line $=$ women. $\quad$ Whole line $=$ men.

So far as I can find, the meaning of these differences has received little attention. A likely view is that they are due to a greater measure of urbanization in the larger countries. This I suggested in a a lecture to the Swedish Medical Association in

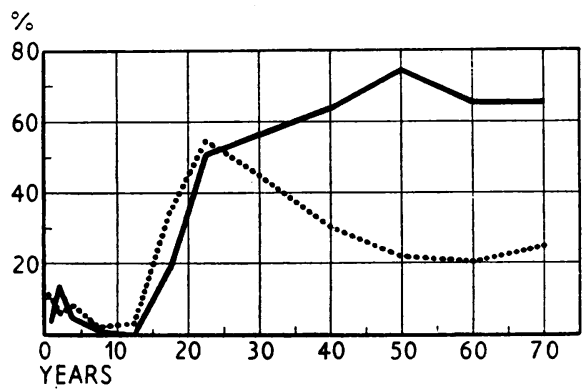

FIG. 14.-Tuberculosis death-rates in Copenhagen (including Frederiksberg), 1944-46.

Dotted line $=$ women. Whole line $=$ men.

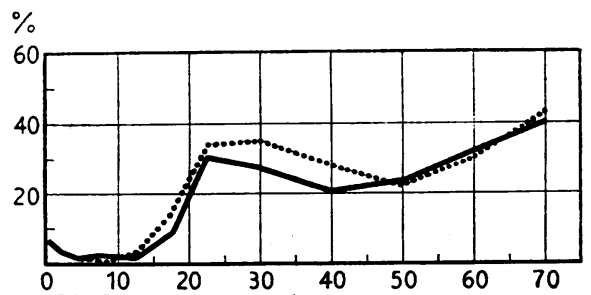

FIG. 15.-Tuberculosis death-rates in rural districts of Denmark, 1944-46.

Dotted line $=$ women. Whole line $=$ men.
$\%$

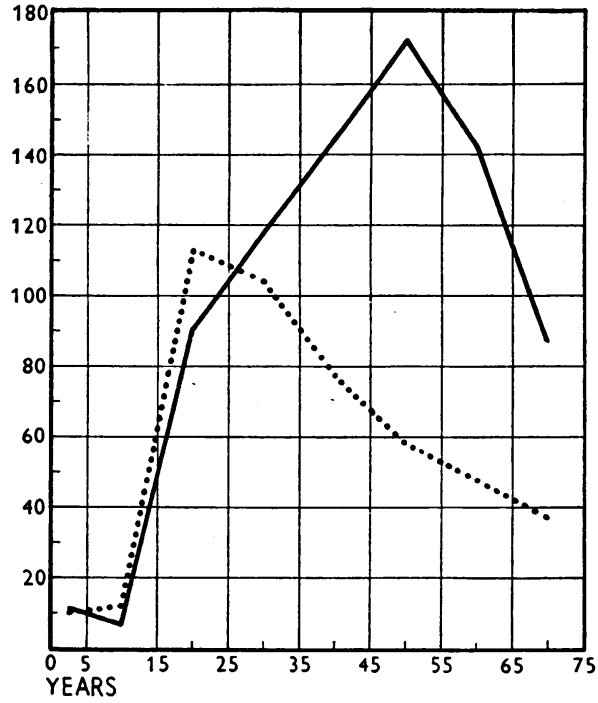

FIG. 16.-Tuberculosis death-rates in urban centres of England and Wales, 1931.

Dotted line $=$ women. $\quad$ Whole line $=$ men

1943 (published 1944). Similar views were propounded by Malthète (1946). In cities men's work brings them into contact with persons suffering from tuberculosis, so that they contract the disease and die to a far larger extent than women. Advancing industrialization naturally entails growing hazards of the same kind for women too, but not to the same degree as for men. If this hypothesis is correct, it should be possible to obtain a difference between conditions in Stockholm and those in other parts of Sweden. Fig. 13 shows that men in Stockholm do indeed

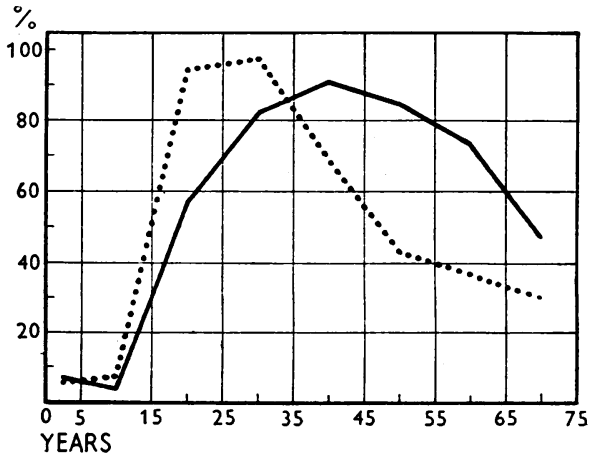

Fig. 17.-Tuberculosis death-rates in rural districts of England and Wales, 1931.

Dotted line $=$ women. Whole line $=$ men. 
conform to the continental pattern, and that in middle age they run far greater risks than women. For Denmark, one can sharply differentiate Copenhagen from purely rural districts, see Figs 14 and 15, which also show the metropolis to be more hazardous in middle-age for men than for women. Contrariwise, the countryside conforms to the curves of the other Scandinavian countries. We may therefore state that the anomalous contour of the Danish curves in Fig. 6 is due to the fact that there Copenhagen, far more than Stockholm in Sweden, dominates the picture as a whole.

As regards the death-rate from tuberculosis in other countries, separate figures for town and country have been obtainable only for England and Wales (Figs 16 and 17). There the sex difference is far greater in the larger cities than in more rural districts, though no figures are available for purely rural districts.

All our assembled data consequently support the hypothesis that infection at the place of work in adult life is of decisive importance for the death-rate among men of middle-age.

In this connexion, it is tempting to take a further step by asking whether such infections are to be considered as first or subsequent infections. The graph of Fig. 3 has some relevance to this issue. In present-day Sweden almost everybody will be infected sooner or later. In a metropolitan population one may surmise that the tuberculin-positive reaction curve will rise more rapidly than in Sweden. If so, reinfections should play a not unimportant part, and the majority of those who die after adolescence should have been infected already at an earlier age. The importance of reinfections has now been the object of discussion for many decades without agreement or decisive proof, and at different times diverse opinions have been more or less fashionable. Though the data under discussion may not be wholly conclusive, it is suggested that reinfections in adult life are of greater importance than has hitherto been thought likely in many quarters.

Different levels of the tuberculosis death-rate in different countries prompt us to examine the following conceivable possibilities:

1. The character of the pathogenic organism may be different in different countries. However, there are no data indicating that the virulence is not the same. Accordingly it is not profitable to discuss this possibility, albeit we cannot with certainty exclude it.

2. The chance of being infected is more or less likely in various countries. That differences may exist in this respect is shown, for instance, by this investigation. Improved communications, increase industrialization, etc., are naturally accompanied by more numerous human contacts. Cleanliness an $\$$ hygiene may lie on different levels. It would seem to be doubtful, however, if differences of this kind can provide the whole explanation.

3. The vital resistance of different peoples mat. be unequal. This resistance is to some extenfo dependent on nutritional status. As nutrition goes down susceptibility goes up. This is shown, fo: example, by higher mortality from tuberculosis at the end of the first world war in Germany and France. It is difficult, however, to trace ant parallelism between the figures given here and the standard of nutrition in various countries. To be sure, the vital resistance of a population may als be genetically determined, but we do not know whys the genetical composition should in this respect be् different in different countries.

It is a fact that the death-rate from tuberculosis has of late decreased. In Sweden, for example, in the towns it was $2 \cdot 8$ per thousand in 1890 , and in the whole country it was 1.6 per thousand in $1910 \mathrm{p}$ 1.03 per thousand in 1930 , and 0.49 per thousan in 1945. The decrease seems to have been almost linear, and it is noteworthy that the death-rate startec to decrease before the new treatments and sanatofia could possibly have had any effect. Even if theses subsequently contributed to the decrease, it difficult to estimate their role; the physician is perhaps inclined to overestimate their importance्尺 and, besides these, two other factors remain to be discussed.

One is the effect of selection; individuals who con tract tuberculosis in a more severe form and shoulde therefore as a rule be particularly susceptible t? tuberculosis often fall ill and die comparativel early, being thereby prevented from procreation? This implies that, in so far as tuberculosis is depen dent on genetical factors, the latter are subject t ${ }^{2}$. selection. Such a mechanism undoubtedly existsô but the recognition of its existence leaves unanswered the question: how great is its effect ? In principle을 it is safe to say that had the disease been relativelys common for several centuries, selection would have. had time to exert its main influence long ago. Forn selection, of course, is most effective in the beginning? When, as a result of it, the frequency of the relevanis genes decreases, its effect becomes progressivel $x^{N}$ smaller and eventually insignificant. In this respecto it is difficult to say anything definite about tubercuo losis. We know that the disease has existed for a very long time; but we know nothing of its? prevalence in bygone days when it could not evento be diagnosed with satisfactory certainty. 
A second mechanism, however, that is certainly of importance, and particularly during recent centuries, is the break up of isolates (Dahlberg, 1948). If susceptibility to tuberculosis is conditioned by recessive genes, the break up of isolates should cause the disease to become more infrequent, since the frequency of allelic genes in duplicate doses thereby decreases. Another way of expressing the same thing is to say that the break up of isolates decreases the frequency of consanguineous marriages, and thereby also the frequency of homozygotes.

Such a mechanism must clearly have played some part, particularly in countries with a more highly developed and extensive industry where cities have grown at the expense of the rural population. Therefore, it seems natural that England should have a lower tuberculosis mortality than Sweden and Norway, regardless of whether English antituberculosis measures are superior or not. Conversely, the high Finnish death-rate from tuberculosis has probably something to do with less extensive break up of isolates in Finland than in other countries, though less developed preventive measures and care for the patients may also make a difference. Denmark's low tuberculosis death-rate is probably due to the fact that the one large isolate, the capital Copenhagen, includes the majority of the population. In the U.S.A. the low mortality from the disease is consistent with the same view, since the population is so largely composed of immigrants, while a comparatiyely high tuberculosis death-rate among Frenchmen is consistent with their strong family bonds. To a fairly large extent marriages are there arranged by the parents, and the frequency of marriages between cousins is unusually high by comparison with other countries of western Europe. In other words, the break up of isolates has probably been less drastic in .France than in other civilized countries during the last half-century.

It seems that many data fit in with the theory suggested by the author, and that the break up of isolates must have had at least some importance for the lowering of the tuberculosis death-rate in recent times. Within Sweden itself, we find signs of the effect of the break up of isolates. For mortality from tuberculosis is highest in the northern parts of the country where the isolates are small and comparatively well defined. It is lowest, on the other hand, in central and southern Sweden where isolates are larger and patients better cared for. If the break up of isolates affects tuberculosis mortality, it should also affect general mortality in so far as the latter is genetically conditioned.

\section{REFERENCES}

Dahlberg, G. (1944a). "Mathematical Methods for Population Genetics." Basle and New York. 39, 10 . (1944b). Svenska NatFören. Tuberk. Kvart., Malthète, R., (1946). Rev. Tuberc., 10, 302. 